\title{
Ensino de Sociologia e Cultura Escolar
}

\author{
Marcelo Rodrigues Conceição*
}

Diego Montanini Cardeal**

\section{Resumo}

0 presente artigo apresenta uma análise sobre o lugar que o ensino de sociologia tem ocupado em relação às demais disciplinas do ensino médio, após seu retorno como disciplina obrigatória, em 2008, e a reforma do ensino médio em 2017. Tomando por base estudos sobre cultura escolar e história das disciplinas escolares, as análises foram efetuadas abrangendo duas abordagens: exterior à escola, em que se aponta o histórico da presença da sociologia nos currículos da educação básica no Brasil e o papel sugerido pelos documentos oficiais; interior à escola, em que se apresenta o entendimento sobre a sociologia na visão de professores e estudantes de uma escola pública. Foi possível constatar que a sociologia ainda não conseguiu ser incorporada à cultura escolar de maneira semelhante às demais disciplinas, o que impede que seja vista como importante para a formação dos estudantes.

Palavras-chaves: ensino de sociologia, disciplinas escolares, cultura escolar.

* Professor adjunto do Instituto de Ciências Humanas e Letras (ICHL) da Universidade Federal de Alfenas (Unifal-MG). Lidera o grupo de pesquisas “Sociedade Industrial: processos e teorias sociais". E-mail: marceloconc@yahoo.com.br.

** Licenciado em Ciências Sociais pela Universidade Federal de Alfenas (Unifal-MG). Mestrando do Programa de Pós-Graduação em Educação da Faculdade de Filosofia Ciências e Letras de Ribeirão Preto - USP (USP-RP). E-mail: diego_adu@hotmail.com 


\section{T eaching of Sociology and School Culture}

\section{Abstract}

This article presents an analysis about the place that sociology teaching has occupied in relation to the other subjects of High school after its return as a compulsory, in 2008, and high school reform in 2017. Based on studies on school culture and history of school subjects, Were carried out covering two approaches: outside the school, which points out the history of the presence of sociology in the curricula of basic education in Brazil and the role suggested by the official documents; Interior to the school, which presents the understanding about sociology in the view of teachers and students of a public school. It was possible to verify that sociology has not yet been incorporated into school culture, in a way similar to the other disciplines, which prevents it from being seen as important for the formation of students. Keywords: sociology teaching, school subjects, school culture.

\section{Enseñanza dela Sociología y la Cultura Escolar}

Resumen

En este artículo se presenta un análisis del lugar que la enseñanza de la sociología ha ocupado en relación a otras materias de la escuela secundaria, después de su regreso como materia obligatoria, en 2008, y la reforma de la escuela secundaria en 2017. Sobre la base de los estudios sobre la cultura escolar y la historia de las materias escolares, los análisis fueron hechos abarcando dos enfoques: fuera de la escuela, y en ese momento se presenta el historial de la presencia de la sociología en los programas de educación básica en Brasil y el papel sugerido por los documentos oficiales; dentro de la escuela, que presenta la comprensión de la sociología en la visión de los estudiantes y profesores de una escuela pública. Se encontró que la sociología no ha logrado 
ser incorporada en la cultura escolar, del mismo modo que otras disciplinas, lo que impide que ella sea vista como una disciplina importante para la formación de los estudiantes.

Palabras clave: enseñanza de la sociología, las materias escolares, la cultura escolar.

\section{Introdução}

0 retorno da disciplina de sociologia, de forma obrigatória, ao currículo do ensino médio, a partir de 2008, e a indicação de sua retirada desta condição, efetuada pela reforma desse mesmo nível de ensino, em 2017, exigem reflexão sobre o papel dessa disciplina no ensino brasileiro. Neste trabalho são apresentadas discussões e análises sobre como a sociologia é compreendida em relação às demais disciplinas do currículo, em dois aspectos: externo e interno à escola, de maneira relacionada. No aspecto externo são destacados o histórico sobre a presença da disciplina nos currículos escolares e as proposições apresentadas pelos documentos oficiais sobre o papel desejado para a sociologia. No aspecto interno, por meio de observações sobre o cotidiano da sala de aula, são apresentadas situações que demonstram o que pensam, como agem e qual o entendimento de professores e estudantes sobre o significado da sociologia no ensino médio.

O interesse na questão se originou das discussões que ocorreram em algumas disciplinas do curso de Ciências Sociais - Licenciatura da Universidade Federal de Alfenas (Unifal-MG), sobre as teorias e concepções de: cultura, cultura escolar, história das disciplinas escolares, políticas educacionais e do ensino de sociologia. De outra parte, foi incentivada pela participação no Programa Institucional de Bolsas de Iniciação à Docência (Pibid) ${ }^{1}$,

10 programa foi criado, em 2007, pela Coordenação de Aperfeiçoamento de Pessoal de Nível Superior (Capes) e tem objetivos diretamente vinculados à valorização dos cursos de licenciatura e à formação dos futuros professores na escola pública e para a escola 
efetuada em algumas escolas públicas de uma cidade do sul do estado de Minas Gerais, por meio do acompanhamento de aulas de várias disciplinas, de observações sobre o funcionamento e a organização da escola, de conversas com professores e estudantes sobre a disciplina de sociologia. Tais atividades propiciaram suscitar constantes discussões entre os autores deste trabalho sobre as práticas vivenciadas no cotidiano escolar.

Os conceitos sobre cultura escolar e história das disciplinas escolares visam auxiliar na compreensão do lugar que a disciplina tem ocupado na escola, de acordo com a atuação de professores e estudantes.

\section{Cultura, cultura escolar e disciplina escolar}

O conceito de cultura é um dos mais discutidos na área das Ciências Sociais. Deixando de lado a amplitude, a abrangência e as controvérsias de utilização (antropológica e sociológica), parte-se da seguinte utilização:

Nesse sentido amplo, podemos dizer que a cultura como qualidade genérica, como atributo universal da espécie humana, na condição que a distingue de todas as outras espécies animais, é a capacidade de impor ao mundo novas estruturas (Bauman, 2012, p. 150).

Weber (2006) foi um dos primeiros sociólogos que direcionou parte de seus estudos e de sua metodologia para a importância da cultura na análise das formas de comportamento dos sujeitos e dos grupos sociais. É através da cultura que os sujeitos elaboram determinados significados a respeito do mundo social que os rodeia e criam certas formas de condução de vida, o que, para

pública, por meio de atividades planejadas e executadas entre os cursos de licenciatura e as escolas parcerias, em cada área do conhecimento. 
Weber (2006, pp. 82-83), torna a cultura imprescindível para se realizar uma análise sociológica da realidade empírica.

A realidade empírica, coletada por meio de observações e de conversas com os professores e estudantes, foi vivenciada no interior das escolas. Observou-se que a compreensão sobre o papel da sociologia pode ser pensada como parte de uma cultura específica, que é a escolar.

Para Viñao (2000, p. 121) as escolas se modificam e são uma combinação de manutenção das tradições e de mudança, proporcionadas por decisões externas, condicionantes tecnológicos e pela cultura escolar, entendida como uma série de práticas consolidadas ao longo de um tempo:

[...] un conjunto de modos de hacer y pensar, de creencias y prácticas, de mentalidades y comportamentos compartidos en el seno de las instituiciones educativas, que se transmiten a los nuevos miembros de la comunidad escolar, en especial a los profesores y a los estudiantes, y que proporcionan estrategias para integrarse en las mismas, interactuar y llevar a cabo, sobre todo en aula, las tarcas cotidianas que de cada uno se esperan, así como, al mismo tiempo, para hacer frente a las exigencias y limitaciones que implican o conlievan $^{2}$ (Viñao, 2000, p. 121).

A cultura escolar pode ser definida como:

[...] um conjunto de normas que definem conhecimentos e condutas a inculcar e um conjunto de práticas que permitem a transmissão desses conhecimentos e a incorporação

2 Tradução livre: um conjunto de modos de fazer e pensar, crenças e práticas, mentalidades e comportamentos compartilhados dentro das instituições educacionais, que são transmitidos aos novos membros da comunidade escolar, em particular, aos professores e aos estudantes, e que proporcionam estratégias para integrá-los, interagir e conduzi-los, especialmente em sala de aula, às características cotidianas que se esperam de cada um, bem como, ao mesmo tempo, para satisfazer os requisitos e limitações que implicam ou convalidam. 
desses comportamentos, normas e práticas coordenadas a finalidades que podem variar (Julia, 2001, p. 10).

Para se pensar em analisar a cultura escolar há que ingressar no interior das salas de aula, visando, segundo Warde e Carvalho (2000, p. 14), apanhar os dispositivos de organização e o cotidiano das práticas e colocar em perspectiva a atuação dos agentes educacionais, levando em consideração algumas categorias de análise como profissão docente, formação de professores, currículo e práticas de leitura e escrita.

Na visão de Julia (2010, p. 19) há três eixos a percorrer para se compreender a cultura escolar: 1) interessar-se pelas normas e pelas finalidades que regem a escola; 2) avaliar o papel desempenhado pela profissionalização do trabalho docente; 3) interessar-se pela análise dos conteúdos ensinados e das práticas escolares. De maneira geral, são destacados nesta análise os eixos um, em que se analisam as finalidades propostas pelos documentos oficiais, e três, em que se destacam as situações do cotidiano escolar em relação à disciplina sociologia, que, respectivamente, correspondem às questões externas e internas à escola.

Julia (2010, p. 13) propõe que ao nos voltarmos para o funcionamento interno da escola, destaquemos a importância da história das disciplinas escolares, em relação aos conteúdos ensinados e às práticas de ensino. A escolha da autora pela análise dos conteúdos ensinados e das práticas escolares se deve ao fato de que as disciplinas escolares seriam, segundo Chervel (1990), produtos específicos da escola. Nesse sentido, as observações das aulas de sociologia indicam, de certa forma, como vem se dando a caracterização da disciplina.

As disciplinas escolares são inseparáveis das finalidades educativas e se constituem como um conjunto complexo que não se reduz aos ensinos explícitos e programados. Os conteúdos a serem ensinados são importantes na constituição das disciplinas, 
mas, como destaca Chervel (1990, p. 187), há um caráter mais amplo que é colocar os ensinos em relação às finalidades e aos resultados obtidos para:

[...] fazer aparecer a estrutura interna da disciplina, a configuração original à qual as finalidades deram origem, cada disciplina dispondo, sobre esse plano, de uma autonomia completa, mesmo se analogias possam se manifestar de uma para outra (Chervel, 1990, p. 187).

Para Chervel (1990, p. 191), a figura do professor é central no processo de transformação das finalidades em ensino, sendo pertinente verificar como ele se relaciona com estas finalidades, impostas de fora da escola, e como as interpreta e as transmite aos estudantes em sala de aula.

De acordo com Chervel (1990, p. 183-184), as disciplinas escolares não são uma adaptação das ciências de referência e nem mesmo a sua vulgarização, contrapondo a ideia de transposição didática. A argumentação do autor é a de que não podemos analisar as disciplinas escolares como uma simples "vulgarização" das ciências de referência, porém, não podemos negar a relação existente entre as disciplinas escolares e as disciplinas acadêmicas das ciências de referência, ou seja, a relação existente entre os saberes escolares e os saberes acadêmicos ou científicos.

Tomando por base as indicações de Chervel (1990), as análises sobre a história da disciplina, as finalidades propostas nos documentos oficiais e a atuação dos professores ganham relevo para a discussão proposta.

É importante ressaltar que as perspectivas de análise defendidas por Julia (2001, p. 10), também enfatizadas por Viñao (2000) e Chervel (1990), em direção ao interior das escolas, não implicam em um abandono das análises macropolíticas, ou melhor, da relação existente entre a escola e outras instituições que tam- 
bém dizem respeito ao plano cultural, como a religião e o Estado. Tal perspectiva vai ao encontro da abordagem efetuada pela denominada Nova Sociologia ${ }^{3}$ da Educação, NSE, que centra estudos na relação escola-sociedade e propõe um olhar sobre a sala de aula, visando compreender as micro relações estabelecidas entre os sujeitos envolvidos nos processos educacionais, porém, sem deixar de atentar para as conexões existentes entre diversos aspectos que influenciam a vida escolar, como: os mecanismos de produção e reprodução social, relacionados às questões de ideologia e poder, e os momentos históricos que interferem nas maneiras de se pensar a sociedade e, logo, a educação. Tais aspectos fizeram com que nos estudos sobre o cotidiano das escolas passassem a ser enfatizadas questões sobre: o currículo, as representações de professores, a interação pedagógica, os processos de interação em sala de aula e a relação direta com a estrutura social, com destaque para o papel do Estado.

Apple (1989, p. 45) destaca que para entender como as ideologias operam nas escolas há que se ter um olhar na vida cotidiana, com atenção às lógicas pelas quais os modos de controle são impulsionados por meio de formas assumidas pelo currículo e não somente pelo conteúdo: "E essa relação entre forma e conteúdo será crucial na minha análise da reprodução e da contradição". 0 currículo é visto, também, como um instrumento de poder na preservação da sociedade em sua atual configuração devendo, segundo Apple (1989, p. 46), ser questionado seu conteúdo: o que faz e o que não faz parte dele, e a forma como está organizado, em termos de cultura e do próprio conhecimento.

Os conhecimentos introduzidos nas escolas são selecionados e organizados por meio de um conjunto de princípios e valores provenientes de algum interesse, representam determinadas visões de mundo: 
[...] se devemos entender por que o conhecimento de apenas alguns grupos foi primeiramente representado nas escolas, precisamos ver os interesses sociais que em geral orientaram a seleção e a organização do currículo. Os interesses sociais e econômicos que serviram como a base para a atuação dos mais influentes especialistas em currículo não eram neutros nem fortuitos. Eles incorporavam compromissos com estruturas econômicas e políticas educacionais específicas que, quando postas em prática, contribuíram para a desigualdade. A política educacional e cultural e a visão da forma como deveriam operam as comunidades e de quem deveria ter poderes nelas serviram de mecanismos de controle social. Esses mecanismos fizeram pouco para aumentar a relativa eficiência econômica ou cultural desses grupos de pessoas que ainda hoje detêm pouco poder (Apple, 1982, pp. 97-98).

Apple (2008, p. 28) aponta um percurso a ser efetuado nos estudos sobre a educação que vão desde o contexto educacional, percorrendo currículo, as salas de aula, a escolarização familiar, os movimentos sociais até as políticas e reformas educacionais. Indica ser o Estado um "ingrediente especial" em sua análise, pois percebeu:

[...] que o poder, a quantidade e o alcance da regulação e da intervenção do estado na economia e no processo social global tendem a crescer, em parte, como uma função do "desenvolvimento gradual do processo de acumulação de capital", da necessidade de consenso e de apoio popular em relação a esse processo e da corrente e continuada desclassificação das pessoas, através da reorganização do discurso político, reelaborado agora em torno dos indivíduos enquanto agentes econômicos, entre outras estratégias (Apple, 1989, p. 43).

Young (2011), ao analisar as reformas educacionais na Inglaterra nos anos de 2000, afirma que se quer dar sentido à importância da educação em uma sociedade do conhecimento, em que este seja tratado como central, o currículo deve ser basea- 
do nele e nas disciplinas que o compõem. Tal posição, segundo o próprio autor (2011, p. 619), se originou no entendimento que a centralidade da disciplina pode permitir, como tem ocorrido, que estudantes oriundos de classes trabalhadoras ou do gênero feminino sejam bem-sucedidos na escola. Dessa maneira, o currículo centrado nas disciplinas seria a maneira mais confiável, conhecida até hoje, de se transmitir e adquirir conhecimento:

[...] as disciplinas como sua sequência, seu ritmo e sua seleção de conteúdos e atividades são o que mais nos levam, em educação, a oferecer aos estudantes acesso a um conhecimento confiável. Em outras palavras, idealmente, as disciplinas escolares expressam valores universais que tratam todos os seres humanos como iguais e não como membros de diferentes classes sociais, grupos étnicos ou meninos e meninas. [...] 0 enfraquecimento da base de disciplinas do currículo tornará mais difícil para os estudantes distinguirem entre "objetos de pensamento", ou conceitos que constituem um currículo, e suas experiências (Young, 2011, p. 621).

As políticas curriculares educacionais são desenvolvidas em consonância com os contextos sociais, políticos e econômicos, o que na visão de Young (2011, p. 610) fez com que os currículos fossem direcionados à solução de problemas sociais e aos interesses dos estudantes, deixando em segundo plano o papel educativo. Dessa forma, o conhecimento incluído no currículo deve ser baseado em conhecimento especializado proveniente de comunidades de pesquisadores. A argumentação de Young (2011, p. 615), em defesa do currículo baseado em disciplinas, se centra na separação entre objeto de pensamento e lugar de experiência, em que as disciplinas seriam as ferramentas que permitiriam passar da experiência a formas mais elaboradas de pensamento. Os conceitos elaborados nas áreas de conhecimento que sustentam as disciplinas são diferentes dos conceitos do dia a dia, são eles que nos permitirão fazer generalizações, a partir de particularidades. 
Segundo ao autor, é o conhecimento da disciplina que fornece autoridade ao professor, já que o mundo cotidiano não é o mundo da escola, não está dividido em matérias ou disciplinas, por isto a identificação das disciplinas é fator importante, principalmente para os estudantes menos favorecidos que não têm muita experiência em tratar o mundo:

As disciplinas, com suas fronteiras para separar aspectos do mundo que foram testados ao longo do tempo, não só oferecem a base para analisar e fazer perguntas sobre o mundo, como também oferecem aos estudantes uma base social para um novo conjunto de identidades como aprendizes. Com as novas identidades referentes às disciplinas, que os estudantes adquirem pelo currículo, acrescentada àquelas que vieram para a escola, eles têm mais probabilidades de serem capazes de resistirem ao senso de alienação de suas vidas cotidianas fora da escola, ou, ao menos, melhor lidar com ele (Young, 2011, p. 617).

A teoria do currículo, portanto, nos apresenta perspectivas de análises importantes para tratar da presença da sociologia no ensino médio, já que se direcionou às formas de hierarquização e distribuição dos saberes escolares desenvolvida pelas políticas educacionais, destacando o papel do conhecimento, dos professores e das relações de ensino-aprendizagem.

O objetivo deste trabalho é apresentar uma discussão sobre o papel da disciplina Sociologia no currículo do ensino médio e as transformações ocorridas ao longo dos anos. Baseado nas perspectivas dos conceitos apresentados sobre cultura escolar (modos de fazer e pensar, crenças e práticas, normas e regras internas), história das disciplinas escolares, organização do currículo, papel do Estado nas políticas e reformas educacionais, busca-se de maneira correlacionada entender como tem sido o percurso da sociologia na educação básica ${ }^{4}$, por meio de um con- 
junto de análise que se inicia com um panorama sobre a história da disciplina nos currículos escolares. Segundo Viñao (2000, p. 121), as modificações nas formas escolares são proporcionadas por decisões externas, condicionantes tecnológicos e pela cultura escolar.

\section{U m panorama sobre a história do ensino de sociologia}

A história da sociologia nos currículos escolares da educação básica apresenta diversas fases e uma trajetória de intermitência. A presença ou ausência nos currículos está diretamente relacionada aos contextos históricos que envolvem definição de políticas educacionais, sempre espaço de disputas de ideias e concepções ideológicas, e da organização do campo das Ciências Sociais ao longo dos anos, também um espaço de disputa.

Segundo Silva (2002, p. 431), desde o final do século XIX, as ideias desta nova área do conhecimento, a Sociologia, foram discutidas nos círculos intelectuais, mas ela só foi introduzida nos currículos escolares, de forma obrigatória, em 1925, com a reforma Rocha Vaz. Diversos aspectos contribuíram, no início do século XX, para a consolidação da sociologia no ensino brasileiro, com destaque para o surto industrial de 1918, proporcionado pelos impactos da primeira Guerra Mundial, e a Revolução de 1930. Tais fatos provocaram mudanças nas esferas políticas, econômicas e culturais, o que deu origem a uma nova atitude crítica na "mentalidade das elites novas, dos movimentos de renovação em diversos setores, como nos das letras e das artes, da educação e da política, e do interesse crescente pelos estudos científicos das realidades sociais" (Liedke Filho, 2005, pp. 381-382). É válido destacar que essa expansão do ensino de sociologia ocorreu na ausência de cursos de formação de professores de sociologia, tornando comum a presença de advogados, médicos e engenheiros cobrindo esta ausência (Moraes, 2011, p. 362). 
Na década de 1930 houve o processo de institucionalização da Sociologia como ciência, com a criação da Escola Livre de Sociologia e Política e a abertura do curso de Ciências Sociais na Universidade de São Paulo e na Universidade do Distrito Federal, ambas em 1934. É importante salientar que esse processo de institucionalização ocorreu no contexto de um governo que adquiriu poderes ilimitados em consequência da legitimidade adquirida pela Revolução de 1930.

Em 1942, foi instituída a Lei Orgânica do Ensino Secundário, que marcou o fim da obrigatoriedade do ensino de sociologia nas escolas secundárias ${ }^{5}$ brasileiras. 0 fim da obrigatoriedade, segundo Stempkowski (2010, p. 29), se dera desde a decretação do Estado Novo em 1937, em que o pensamento católico conservador ganhou força, em detrimento do pensamento renovador proposto pelo movimento da Escola Nova. Para Moraes (2011, p. 364), naquela época as Ciências Sociais e a Sociologia ainda não haviam alcançado o prestígio e a legitimidade que outras ciências mais antigas e tradicionais conquistaram, o que não garantiu o seu lugar no novo currículo: "os defensores da Sociologia não conseguiram convencer a burocracia educacional quanto à necessidade de sua presença nos currículos".

No ano de 1961 foi aprovada, após 13 anos de tramitação no congresso, a primeira Lei de Diretrizes e Bases da Educação (LBD) 4.024/61. A sociologia tornou-se uma disciplina opcional entre mais de uma centena, o que fez com que se mantivesse praticamente fora do currículo. Nessa época, a decisão de ofertar a disciplina cabia às escolas, porém, como estas não dispunham de recursos e, possivelmente, com certo receio das repressões militares, geralmente ofertavam apenas as disciplinas obrigatórias.

5 A Lei orgânica de 1942 definiu o ensino secundário como posterior ao primário e composto por dois ciclos: ginasial, correspondente ao ensino fundamental, anos finais atualmente, e dois cursos paralelos: o curso clássico e o curso científico que correspondem ao ensino médio nos dias atuais. 
Alguns acontecimentos influenciaram, anos depois, o aprofundamento dessa exclusão, como perseguições e exílio de intelectuais e cientistas sociais do Brasil, a partir de 1968, e a chegada de livros e de artigos produzidos fora do país, nas Universidades, com temas relacionados à democracia e ao regime ditatorial. Entre os anos de 1971 e 1982, segundo Moraes (2003, p. 7), a disciplina de sociologia também encontrou dificuldades para ser incluída nos currículos escolares devido ao preconceito existente no período da Ditadura Militar, que confundia a Sociologia com o socialismo.

O processo de redemocratização do país, iniciado no final dos anos de 1970, em que houve grande representação de movimentos sociais, fez com que a sociologia começasse a ser reintroduzida paulatinamente nas escolas, em diferentes estados e cidades. A promulgação da Constituição de 1988, considerada como uma Constituição cidadã, contribuiu para a discussão sobre a necessidade da presença obrigatória da sociologia. Porém, nos anos seguintes, ao acompanhar a trajetória da elaboração da nova LDB, observa-se que o texto aprovado restringiria os direitos consagrados na Constituição de 1988, pois reformulou as responsabilidades e atribuições do Estado, do mercado e da sociedade no âmbito educativo, segundo Krawczk (2005, p. 808).

O início dos anos de 1990 marcou a introdução de políticas neoliberais no país, influenciadas e comandadas pelo Banco Mundial, de acordo com Torres (1996, p. 131), em que se destaca a retirada do Estado e a centralidade do mercado para a condução da educação, sustentada por quatro eixos: acesso, equidade, qualidade e redução da distância entre reforma educativa e econômica. As reformas educacionais dos anos de 1990 definiram formas mercantis de delegação de poderes e de relação de demanda, por meio de uma:

[...] nova forma de organização e governação do sistema educacional e da escola, ao adotarem os princípios do mercado como indicador das realizações em todas as esferas 
sociais e ao ressignificar o conceito de cidadania enquanto consumidor (Krawczk, 2005, p. 803).

No cenário dos anos de 1990, o ensino de sociologia teve dificuldades em se fazer presente de maneira obrigatória. A LDB de 1996, Lei 9.394, dentre outros assuntos, tratou sobre a presença das disciplinas de sociologia e de filosofia nos currículos, mas de forma ambígua e abstrata ao expressar que deveria se garantir "o domínio de conhecimentos de Filosofia e Sociologia necessários ao exercício da cidadania" (Brasil, 1996). Tal tratamento não obrigava a presença da disciplina nos currículos escolares. Em 1997, começou a tramitar na Câmara dos Deputados o Projeto de Lei (PL) 3.178, que visava a alteração do artigo 36 da LBD, propondo de fato a obrigatoriedade das disciplinas de sociologia e filosofia no ensino médio. Após ser aprovado na Câmara e no Senado, em 2001, o então presidente Fernando Henrique Cardoso, vetou o projeto de lei.

Em 2008, o Congresso aprovou o PL 1.641/03, que foi posteriormente sancionado pelo presidente em exercício, José de Alencar, como a Lei 11.684, que alterou a LDB e tornou obrigatórias as disciplinas de sociologia e filosofia em todos os anos do ensino médio. A partir de então, as escolas de ensino médio com três anos de duração teriam até o ano de 2011 para efetuarem a inclusão e aquelas em que o tempo de duração era de quatro anos teriam até 2012 .

No final do ano de 2016 o Governo federal encaminha ao Congresso dos deputados um projeto de reforma do ensino médio. Em meio a muitas discussões acerca dos propósitos, da legitimidade do governo, das possibilidades de implementação e dos impactos a serem gerados na formação dos estudantes, aconteceram protestos de estudantes contrários à reforma. Entretanto, no início de 2017, o projeto foi aprovado pelo Congresso e a lei sancionada pelo Presidente da República. No que se refere ao ensino de sociologia, a primeira proposta era de oferecer conte- 
údos relativos à ela, mas não como disciplina obrigatória, o que gerou protestos por parte de educadores e profissionais da área. Outras disciplinas também foram fruto da mesma intenção, como artes, educação física e filosofia. Ao final prevaleceu que, de acordo com o Art. 35-A, incorporado à LDB de 1996, no $\S 2^{\circ}$ : "A Base Nacional Comum Curricular referente ao ensino médio incluirá obrigatoriamente estudos e práticas de educação física, arte, sociologia e filosofia" (Brasil, 2017). A Lei só será colocada em prática em 2018, pois depende da definição da Base Nacional Comum Curricular (BNCC), que está em elaboração. Ao voltar ao patamar anterior, será fomentada a desvalorização do ensino de sociologia, pois haverá a necessidade de que os conteúdos sociológicos estejam presentes no currículo, mas a disciplina não será necessariamente obrigatória, podendo ocorrer uma diminuição de carga horária, além da possibilidade de que docentes não formados em Ciências Sociais ministrem os conteúdos sociológicos em sala de aula.

0 que se pode concluir é que a sociologia nunca conseguiu se firmar como disciplina obrigatória na educação básica. Moraes (2011, p. 367) critica a forte visão ideologizada do fenômeno, mostrando as contradições de tal discurso, como por exemplo, o fato da Reforma de 1925, que garantiu a obrigatoriedade do ensino de sociologia, ter sido realizada em um governo caracterizado como autoritário, o de Arthur Bernardes, ou seja, o que impede uma analogia direta entre a presença da sociologia em governos apenas orientados por princípios democráticos (Moraes, 2011, p. 362). 0 veto efetuado em 1990 à obrigatoriedade da disciplina se deu em governo eleito democraticamente, e pode ser considerado outro momento em que não se sustenta apenas a questão ideológica.

Segundo Moraes (2011, p. 367), existe aspectos e tensões internas do campo das Ciências Sociais, como os objetivos e ideias acerca da própria ciência sociológica e da disciplina escolar, que necessitam de maior aprofundamento. No caso da designação 
da disciplina como sempre aliada aos anseios democráticos, o autor aponta para o fato de que até os anos 1940 a mesma possuía caráter mais conservador e de controle social do que de emancipação e crítica.

Das mais importantes questões sobre a presença da disciplina é o fato de que as políticas educacionais que também envolvem disputas políticas e ideológicas de grupos que disputam o Estado envolveram, em linhas gerais, segundo Santos (2202, p. 154) nos últimos cem anos, duas concepções pedagógicas: a clássica ou humanista e a científica ou pragmática. As reformas Rocha Vaz (1925), Francisco Campos (1931) e Paulo Renato (1998), nos anos de 1920, 1930 e 1990, respectivamente, indicaram um ensino de sociologia como um instrumental teórico-prático, uma tecnologia de preparação dos jovens para solução de problemas sociais. Parece que a Reforma do ano de 2017 seguirá o instrumentalismo tecnológico.

Segundo Moraes (2011, p. 363) o fato da sociologia como disciplina do ensino médio ter surgido antes da criação dos cursos de Ciências Sociais seria um dos fatores para a distinção que é efetuada entre as ambas. Entretanto, Moraes destaca haver uma razão mais forte que estaria ligada aos objetivos dos cursos superiores que seria a de formar pesquisadores e quadros para o desenvolvimento do país nas iniciativas pública e privada, tornando a formação e professores algo de menor valor, menor categoria, já que a massificação/expansão educacional não foi efetuada nos anos de 1930 e 1940.

A desvalorização do campo da educação também pode ser um fator que contribui para a dicotomia entre bacharelado e licenciatura nos cursos de Ciências Sociais, o que ajuda a reforçar a visão da educação ou do ensino de sociologia com menos prestígio. Ressalta-se que a dicotomia não é peculiaridade das Ciências Sociais, pois se faz presente em outras áreas do conhecimento. Entretanto, reconhece-se que há peculiaridades do campo muito 
relacionadas ao histórico de tentativas de legitimação tanto da área de conhecimento enquanto ciência como do ensino de sociologia. Segundo Silva (2002, p. 6), a partir da década de 1960, os intelectuais distanciaram-se pouco a pouco dos debates sobre o ensino das ciências sociais em geral e, em particular, no campo escolar. Os cientistas sociais do período de 1930 a 1960 viam a institucionalização da disciplina escolar como fator de consolidação da Sociologia no país, ao passo que para os cientistas sociais pós 1960, a consolidação da Sociologia no Brasil não possuía vinculação com o campo escolar.

No plano interno às Ciências Sociais, Santos (2002, pp. 156-157) aponta alguns argumentos que ajudam a compreender parte da disputa sobre a formação do cientista social, relacionada à visão de mundo e de concepção dos cientistas sociais. Para um grupo, a formação de especialista, no caso de sociólogo, deve preceder a de professor. Já para o outro grupo seria necessário que a formação do professor estivesse presente desde os primeiros contatos com os conceitos, teorias e métodos de investigação da área. Talvez essas divisões fiquem menos acentuadas com o aumento significativo dos espaços de discussões sobre o ensino de sociologia, em grupos de trabalhos de algumas das principais entidades da área como, a Sociedade Brasileira de Sociologia, a SBS.

É possível analisar que a disciplina, desde sua chegada, esteve presente em determinados momentos, mas não se firmado como componente obrigatório dos currículos da educação básica ao longo dos anos. Seja por problemas ideológicos, seja por problemas internos ao próprio campo das Ciências Sociais, o fato é que a intermitência da disciplina de sociologia nos currículos escolares contribuiu, ao lado de outros aspetos, para que a disciplina não fosse incorporada à cultura escolar. 


\section{As finalidades do ensino de sociologia}

Os documentos oficiais, conforme destaca Julia (2010, p. 19), não podem ser os únicos elementos a se levar em consideração ao analisar o ensino de sociologia, mas é preciso adicioná-los ao conjunto de aspectos que compõe o quadro da disciplina. A LDB de 1996 e os Parâmetros Curriculares Nacionais (PCNs) indicam o papel que o ensino de sociologia deve realizar no ensino médio e apresentam os conteúdos a serem trabalhados e algumas propostas didático-metodológicas.

A LDB de 1996 sugeriu que o conhecimento de sociologia estivesse relacionado ao exercício da cidadania, ou seja, indicou haver uma estreita ligação da necessidade em se ter sociologia na educação básica para fins específicos, relacionados a aspectos constitucionais do exercício de tal intento, apesar de apontar não ser ela a única disciplina a dar conta deste amplo aspecto. É interessante notar que o mesmo documento traz como objetivo para o ensino médio a preparação básica para o trabalho, ou seja, uma finalidade mais instrumental, estando o ensino de sociologia sujeito a se adequar aos ditames do capital no que diz respeito a formar indivíduos aptos para ingressar no mercado de trabalho.

Com a implantação da LDB de 1996 foram organizados novos PCNs em 1999, o anterior era de 1961. O PCN do ensino médio (PCNEM) em sua parte $\mathrm{IV}^{6}$, denominada de Ciências Humanas e suas Tecnologias, que engloba as disciplinas de filosofia, geografia, história e sociologia, apresentou um capítulo reservado à sociologia, "Conhecimentos de sociologia, antropologia e política", dividido em duas partes principais. A primeira denominada "Por

6 As demais partes são: Parte I - Bases legais do documento; Parte II - Linguagens, Códigos e suas Tecnologias, é composta pelas disciplinas de Língua Portuguesa, Língua Estrangeira Moderna, Educação Física e Informática. Parte III - Ciências da Natureza, Matemática e suas Tecnologias, apresenta as disciplinas de Física, Química, Biologia e Matemática. 
que ensinar Ciências Sociais" justifica que o estudo das Ciências Sociais no ensino médio tem como objetivo mais geral introduzir o estudante nas principais questões conceituais e metodológicas das disciplinas da área. A segunda parte intitulada "O que e como ensinar em Ciências Sociais" indica os assuntos que devem ser desenvolvidos nas aulas como castas, classes sociais, Estado, relações de poder, dentre outros.

Em 2006, os PCNEMs passaram por reformulações, sendo designados por PCNEM+. Termos anteriormente utilizados como "O que e como ensinar" deram lugar para sugestões de quatro eixos temáticos a serem trabalhados. No primeiro constaram temas como o indivíduo e sociedade, em que podem ser introduzidos conceitos como família, escola, igreja, conhecimento científico versus senso comum, justiça, socialização e outros processos sociais. 0 segundo eixo temático se refere à cultura e sociedade, em que podem ser trabalhadas temáticas como a indústria cultural no Brasil, os movimentos de contracultura e as relações entre cultura erudita e cultura popular, educação e cultura, consumo e alienação e conscientização e cidadania. 0 terceiro eixo se refere à relação entre trabalho e sociedade e sugere temas como os modos de produção ao longo da história, o trabalho no Brasil, as formas de desigualdades, as desigualdades sociais no Brasil, mercado de trabalho, emprego e desemprego e profissionalização e ascensão social. 0 último eixo se refere à política e sociedade em que os temas sugeridos são as relações de poder no cotidiano, a importância das ações políticas, as diferentes formas do Estado, o Estado brasileiro e os regimes políticos, legitimidade do poder e democracia, formas de participação e direitos do cidadão.

De acordo com o PCNEM+ de 2006, a sociologia cumpre importante papel na formação dos estudantes por trabalhar sobre dois aspectos fundamentais para a formação do cidadão e da consciência crítica: a desnaturalização e o estranhamento. 0 significado de desnaturalizar é: 
[...] compreender que a realidade cotidiana é resultado de decisões, de interesses particulares ou coletivos, de ideologias; não é uma tendência natural e imutável e pode ser modificada pela vontade humana" (Brasil, 2006b, p. 317).

Já o estranhamento:

[...] reclama a problematização das questões sociais a partir de situações corriqueiras, comuns, triviais. Estranhar é entender a experiência social para além de sua normalidade, ou seja, é colocar em questão situações vivenciadas todos os dias e tidas como esperadas; é buscar respostas para essa expectativa de normalidade que envolve os fenômenos sociais e os torna inquestionáveis; é assumir postura investigativa frente a um mundo aparentemente conhecido e ordinário (Brasil, 2006b, p. 327).

A análise dos conteúdos curriculares realizada não se embasa na ilusão de que os currículos e seus componentes são neutros, muito menos o conhecimento a ser compartilhado no interior das escolas. Nesse sentido, destaca-se a importância designada por Apple (1982, p. 100) ao papel do senso comum no auxílio ao desenvolvimento de uma ideologia dominante, o que não permitiria que ela se implantasse, pois está diretamente vinculada, nem que seja parcialmente, ao senso comum de cada momento histórico. Apple (1982, p. 100) aponta que muitas proposições de educadores especialistas e intelectuais estão baseadas em ideias liberais voltadas a "ajudar pessoas", mas precisam ser analisadas em outra perspectiva que é a de naturalizar concepções e as terem como consenso, fundadas no senso comum e relacionadas em educação, por exemplo, a comportamento normal ou anormal, seriam funções latentes.

Ao propiciar a aquisição de um olhar que consiga estranhar o que está posto e desnaturalizar os fenômenos que são sociais, o ensino de sociologia pode contribuir para que os indivíduos consigam adquirir uma visão emancipadora a respeito da realidade que os cerca e de seu lugar dentro desta realidade. É preci- 
so entender que o conhecimento não é algo neutro e questionar qual é o conhecimento mais valioso e a serviço de quem ou de qual grupo está? 0 ensino de sociologia se traveste como enciclopédico e se coloca a serviço de uma formação propedêutica, voltada para a formação de alunos da elite preparados para ingressar no ensino superior ou o ensino de sociologia busca servir realmente como um instrumento que propicia uma formação crítica e emancipadora, possibilitando que minorias e classes sujeitadas consigam apreender as causas de tal sujeição e se preparar para exercer sua cidadania de forma autêntica dentro de um Estado de direito? São questões complexas que não fazem parte do objetivo do presente trabalho responder, entretanto, em relação à finalidade do ensino de sociologia, contida nos documentos oficiais, parece que o senso comum, imposto pela ideologia dominante, neste momento de tensão política, parece indicar a utilização para solução dos problemas sociais, logo de ajuda às pessoas.

Os documentos oficiais são fontes de apoio e servem de norteadores para o trabalho do professor, com sugestões de temas e direcionamento de discussões, sendo que a materialização do conhecimento ocorre na escola, mais especificamente nas salas de aula. Sendo assim, na sequência serão apresentados relatos e análises sobre o entendimento da sociologia na sala de aula.

\section{A sociologia na sala de aula}

Antes de iniciar a apresentação das reflexões sobre o ensino de sociologia e o cotidiano da sala de aula é preciso fazer uma ressalva. Viñao (2000, p. 121-122) destaca que não há uma cultura escolar, mas culturas escolares, como: cultura administrativa dos gestores e dos supervisores da educação que se relaciona ao modo de ver as instituições docentes; culturas específicas de acordo com o nível de ensino (superior, médio, fundamental, infantil) e ainda uma cultura de cada unidade escolar com carac- 
terísticas peculiares, mas que podem fazer parte de uma cultura dos professores ou dos estudantes, podendo distinguir-se de culturas próprias de cada nível ou escola. 0 enfoque adotado é direcionado aos relatos acerca do sentido da sociologia de uma escola específica, ou seja, que tem uma cultura que lhe é própria, mas ao mesmo tempo não pode ser isolada de uma cultura geral dos gestores, dos professores e dos estudantes.

Um dos problemas detectados sobre o ensino de sociologia no ensino médio é a pequena carga horária, apenas uma aula por semana. Como para desenvolver as atividades do Pibid era necessário realizar uma parte da carga horária nas escolas e dada a importância em se conhecer as didáticas e estratégias de ensino de diversas disciplinas, houve o acompanhamento de aulas de outras disciplinas, como biologia e física. 0 que num primeiro momento pareceu ser uma dificuldade, a bem da verdade possibilitou que se conhecesse o que pensam os professores de outras áreas sobre a presença da sociologia no ensino médio, além das diferenças e semelhanças entre as formas de tratamento dos estudantes em relação às disciplinas.

Durante o processo de observações das aulas e do cotidiano escolar, foi possível analisar, pelos comentários e atitudes de professores, o desconhecimento que existe sobre o papel a ser exercido pelo ensino de sociologia no currículo das escolas. Nas aulas de biologia a professora sempre perguntava aos $p i-$ bidianos sobre o estudo de conteúdos de Biologia na universidade, mesmo sabendo que pertenciam ao curso de Ciências Sociais. 0 professor de física, por sua vez, sempre questionava o que se faz no curso de Ciências Sociais, quais atividades são desenvolvidas e com quais finalidades. Também interrogava sobre qual disciplina ministraria um licenciado na área. Em algumas reuniões pedagógicas, por exemplo, professores questionavam qual disciplina acompanharia um estudante de Ciências Sociais nas atividades do Pibid. A direção da escola em conversas sobre o andamento das atividades sempre relatava 
as apresentações e a utilização ou organização de laboratórios nas disciplinas de física, química e geografia, dando a entender não saber a distinção entre as áreas ou no que e como a sociologia poderia ser incorporada ao cotidiano da escola. Em vários momentos era indagado o que seria a sociologia, o que ela faz de fato. A impressão, como fica evidente ao perceber que muitos professores de outras áreas ministraram a disciplina, é que ela seja algo do cotidiano, desprovida de necessidade de um conhecimento sistematizado, construído por meio da elaboração de conceitos e teorias, embasados por métodos de pesquisa. Era bastante perceptível a dificuldade em apresentar propostas de trabalho e de receber ideias, pois o senso comum acerca de ser a aula de sociologia um espaço de debates sobre a realidade a desconfigura, já que impede que se efetue produção e transmissão de conhecimento de fatos sociais, metodologicamente, e não apenas discussões.

Quando se afirma que existe certo desprestígio de alguma disciplina escolar, primeiramente se pensa em indisciplina e desinteresse dos estudantes pela mesma, algo que foi visivelmente notado nas aulas de sociologia. Porém, a partir das observações, é preciso salientar que a indisciplina, a falta de interesse pelos conteúdos, as brincadeiras, as conversas, são fatos que fazem parte do dia a dia, independentemente da disciplina. Entretanto, ao mesmo tempo em que alguns aspectos citados acima são comuns em todas as aulas, a importância dada pelos estudantes às disciplinas era diferente. Eles atribuem valores, graus de importância que classificam as disciplinas. Nas aulas de sociologia, os estudantes se mostravam relutantes em realizar as atividades propostas pelo professor. Um simples escrito no quadro, o resumo de uma parte do livro e até a discussão de um texto didático específico eram atividades totalmente rechaçadas pela classe. Os estudantes não demonstraram o mínimo interesse em realizar qualquer atividade. Era muito comum ouvir, nas aulas de sociologia, os estudantes dizerem as seguintes frases: "Afe, pra que eu tenho que estudar isso? Me explica?" "Lá vem esse pro- 
fessor explicar essas coisas malucas, sem pé nem cabeça"; "Essa matéria vai servir pra quê na minha vida?".

Uma das atividades realizadas com os estudantes na aula de sociologia foi a exibição de vários episódios do seriado "Cidade dos Homens", que retrata a vida de dois adolescentes moradores de uma comunidade no Rio de Janeiro. 0 objetivo da atividade era discutir temas e fatos abordados pelo seriado, sob o ponto de vista sociológico, que fizessem parte da vida dos estudantes, para que eles pudessem entender como a sociologia poderia ajudá-los a compreender a realidade social e, consequentemente, formar um pensamento crítico. Porém, nas aulas de preparação para a discussão dos capítulos do seriado os estudantes não se interessavam, não debatiam e poucos copiavam o que o professor escrevia no quadro. Diante da situação, o professor sentava e desistia de dar a aula, ou então ficava dando broncas nos estudantes, pedindo para que pelo menos o texto do quadro fosse copiado nos cadernos, pois valeria nota de participação ao final do bimestre. Os poucos estudantes que copiavam os escritos do quadro ou do livro demonstravam que faziam aquilo porque precisavam de nota ou por obrigação, não entendendo o porquê de estarem estudando tais conteúdos e qual o sentido que teriam em sua vida.

A imagem que os estudantes têm é que o ensino de sociologia não tem um objetivo prático na sequência de suas vidas. É apenas uma disciplina em que se pode fazer o que quer sem que haja uma finalidade estabelecida.

Em outras disciplinas, as atitudes eram parecidas. Porém, apesar dos estudantes demonstrarem falta de interesse e serem indisciplinados, não se queixavam nem questionavam o sentido de estarem presentes, além de desenvolverem as atividades propostas. Os mesmos estudantes que não faziam absolutamente nada na aula de sociologia faziam as atividades nas outras aulas. $\mathrm{Na}$ aula de física, quando o professor adentrava à sala de aula, a 
classe toda murmurava e reclamava, fazia certa bagunça e não demonstrava vontade em aprender as novas fórmulas e teorias. Os estudantes, durante a realização da chamada, pareciam que já começavam a se acostumar ao fato de que teriam que aprender seus conteúdos. 0 professor começava sua aula e em pouco tempo os estudantes pareciam adaptados ao fato de que teriam que prestar atenção e fazer o que o professor pedisse, pois de certa forma a consideravam importante. Após a explicação, o professor sempre indicava uma série de contas a serem resolvidas no quadro. A maioria da sala ficava em silêncio e realizava a atividade. Até mesmo os estudantes que carregavam o rótulo de mais bagunceiros tratavam de fazer as atividades. Alguns até pediam a ajuda do professor. Outro fato interessante é que essa aula de física era na sequência da aula de sociologia. Era curioso observar os mesmos estudantes terem atitudes diferentes, o que pode revelar maior valorização de uma disciplina em relação à outra, ou sugerir que o professor tenha papel relevante na forma como os estudantes atribuem significados e se comportam em relação aos conteúdos.

Parece ser oportuno destacar, baseado em Apple (1989, p. 39), alguns aspectos da resistência de grupos que correm nas várias instituições e não seriam diferentes na escola. Por exemplo, as formas pelas quais os estudantes fazem o tempo passar, matam o tempo, durante as aulas, por meio de diversas situações que podem revelar a contestação ao conteúdo ou a forma de ensino. As questões da resistência e da produção e da reprodução social podem ser mais bem refletidas ao analisar a prática dos professores.

No processo de acompanhamento das aulas de sociologia foram observadas, mais sistematicamente, as práticas de três professores, ao longo de três anos. Os três tinham características que lhes eram particulares, no que diz respeito tanto à forma de lecionar quanto às atitudes e aos gostos pessoais. Havia também um aspecto profissional importante que os diferenciava, a forma 
de contratação: professor efetivo, que era concursado, e contratado, que nem sempre tinha formação na disciplina.

0 primeiro professor era graduado em Filosofia e contratado, apesar de ser efetivo em outra escola na disciplina em que se licenciou. Era um sujeito bastante tímido e, devido à grande bagunça em suas aulas, a voz do professor não era sequer ouvida. Em suas aulas, o único momento em que se ouvia sua voz era na hora da chamada, pois de resto era só bagunça por parte dos estudantes. 0 professor fingia não ver o que estava acontecendo e não tomava atitude alguma para contornar a situação. Ele se virava e escrevia no quadro. Pouquíssimos estudantes copiavam o que era escrito no quadro. Porém, esse professor ficou muito pouco tempo na escola e foram poucas as aulas observadas em sua regência. Uma característica que marcava esse professor era sua apatia, seu desânimo em sala de aula. Parecia que ministrar aula não passava de uma dolorosa obrigação. Ao verificarem a apatia do professor e sua incapacidade em tentar sequer colocar ordem na sala, os estudantes sabiam e diziam que a aula de sociologia era a aula do truco ou a aula da bagunça, pois faziam de tudo, menos aprender os conhecimentos de sociologia. Além disso, os conteúdos trabalhados pelo professor, conceitos básicos como interação social, no quadro ficavam no plano bem superficial, deixando a impressão de que o professor sequer preparava a aula.

Novamente é importante insistir na dificuldade da Sociologia, como disciplina das Ciências Sociais, ser incorporada à cultura escolar pelo fato de que professores de várias áreas a ministravam. Em parte, esse fato se dava pela necessidade admirativa de complementação de carga horária para alguns professores, já que a contratação dos efetivos é baseada em quantidade de aulas, havendo em muitos casos sobre de tempo. Era o aparato burocrático-estatal sobrepondo a importância da organização curricular. Ressalta-se que a partir de 2010 esse quadro começou a mudar, após a obrigatoriedade imposta em 2008, com a 
abertura de concursos e a contratação de professores efetivos para a disciplina. Porém, parece ainda não ter sido tempo suficiente para a absorção e o entendimento da sociologia no interior da escola.

O segundo professor apresentava características bem diferentes do primeiro. Também era contratado, mas cursava licenciatura em Ciências Sociais. Ao acompanhar suas aulas era visível que o domínio de conteúdo era mais bem elaborado que o do primeiro professor. Porém, os estudantes já haviam se adaptado ao fato de que a aula de sociologia era destinada à recreação (jogos e conversas informais) e não ao estudo sistemático de questões sociais. Seria essa uma construção da cultura escolar? Essa foi uma grande dificuldade encontrada pelo professor ao tentar estabelecer um diálogo com os estudantes e tentar compartilhar o conhecimento sociológico. Os estudantes continuavam a entrar em conflito com o professor da disciplina, que acabou cedendo à resistência dos estudantes: "Lá vem esse professor maluco falar as coisas sem pé nem cabeça”. As aulas apresentavam conteúdo importante sobre o papel da sociologia nas relações sociais, no trabalho, mas os estudantes não conseguiam entender do que se tratava, em parte devido à utilização de uma linguagem muito complexa, com a utilização de termos não familiares. Os estudantes ficavam perdidos nas aulas. Apesar de dominar os conteúdos, falar bem, preparar as aulas, parece que não ocorria uma relação entre ensino e aprendizagem. Dessa forma, o professor visivelmente desanimou e começou a ministrar as aulas de forma descompromissada. Até mesmo a forma como se vestia, como se comportava, chamou a atenção dos estudantes, que passaram a ridicularizá-lo, alegando que ministrava as aulas "chapado".

O terceiro professor era efetivo, formado em Ciências Sociais e possuidor do título de mestre em Sociologia. Antes mesmo de iniciar seu trabalho na escola, em uma reunião do Pibid, o professor relatou que não desejava pegar as aulas da escola periférica, mas foi o que a Secretaria Regional de Ensino (SER) havia 
lhe oferecido. Suas palavras revelaram certo estigma em relação à situação socioeconômica do bairro (não central, com altos índices de criminalidade e de pouca infraestrutura pública) e dos moradores onde estava localizava a escola. 0 professor ficou com todas as turmas da escola, do primeiro ao terceiro ano do ensino médio. No início de seu trabalho apresentou um seriado que retratava muitos dos fenômenos que ocorriam na vida dos estudantes. 0 objetivo que era debater com os estudantes conteúdos sociológicos a respeito dos episódios da minissérie não surtiu efeito: os estudantes não se interessaram pela iniciativa e não contribuíram para o andamento das aulas. 0 professor desanimou e passou a ministrar as aulas visivelmente cansado, desmotivado e sem compromisso nenhum com o aprendizado dos estudantes. Não havia sequência nos conteúdos trabalhados de uma aula para outra. 0 professor chegava à sala, abria o livro didático e escolhia um texto para ler com os estudantes. Se eles não colaborassem, ele pedia para os estudantes fazerem um resumo do texto valendo nota. 0 professor escolhia na hora da aula qual conteúdo seria trabalhado, ou seja, não preparava a aula e sequer tinha um objetivo ou uma justificativa para sua aula ou para o ensino de sociologia em geral. Ao tentar marcar uma prova com os estudantes, ouvia-se ecoar em tom uníssono na sala: "Olha aqui meu caderno, não tem "matéria” nenhuma, só tem uma folha e você quer dar prova?". Outra frase que se ouvia bastante nas aulas de sociologia era: "Você não passa nada no quadro, que aula é essa?".

O fato é que as práticas dos professores em sala de aula são percebidas pelos estudantes que observam se a aula foi preparada, se há continuidade no desenvolvimento dos conteúdos, se a autoridade é exercida e estão atentos à didática utilizada. Todos esses aspectos são levados em consideração pelos estudantes para o julgamento da importância ou não de uma disciplina.

A argumentação de Chervel (1990, p. 192) sobre a diferença entre as finalidades impostas e as realmente desenvolvidas acerca 
do papel da disciplina pode ser constatada pelas observações das aulas de sociologia, pois os diferentes professores não seguiam à risca as finalidades impostas para o ensino de sociologia. Tal postura criava disciplinas singulares, de acordo com o professor que a ministrava e com os estudantes que a frequentavam. Outro aspecto importante para Chervel (1990, p. 202) é que as finalidades do ensino de uma disciplina são idênticas para todas as escolas, mas as práticas não. Pode-se dizer que cada escola, cada professor e cada grupo de estudantes fomentam uma disciplina que possuirá singularidades em relação às outras turmas e às outras escolas, o que, de acordo com as exposições acima, devem levar o grupo a refletir sobre o papel da sociologia na Escola, o que, neste momento, parecem algo fora de sentido e estranho ao currículo.

Nos apontamentos sobre a relação entre os professores de sociologia e os estudantes, ficou bastante longínqua a discussão sobre os conteúdos. Há muitas dificuldades em fazer com que aconteça a aula. Há dificuldade para que se inicie e se conclua a apresentação e a discussão de conteúdos, já que o fato de se ter apenas uma aula por semana ajuda a impedir o desenvolvimento dos conteúdos propostos pelos PCNs.

Novos ensinos, de acordo com Chervel (1990, p. 192), podem surgir nas salas de aula sem terem sido explicitamente formulados pelos documentos ou diretrizes educacionais. Chervel (1990, p. 198) argumenta que a escola possui autonomia em relação à prática do ensino, já que é livre para regular suas modalidades, que lhe são impostas pelas finalidades advindas da sociedade. Nesse sentido, é preciso deixar de desanimar e buscar fortalecer o papel do ensino de sociologia nos currículos escolares.

Ao se pensar na capacidade que os indivíduos têm de modificar as situações vivenciadas e tomando por base as definições de cultura de Bauman (2012, p. 150) e de cultura escolar de Viñao (2000, p. 121), apresentadas anteriormente, talvez seja neces- 
sário que, principalmente, os professores de sociologia tenham consciência da necessidade de se impor novos rumos e perspectivas dentro do espaço escolar, de maneira a criar uma cultura que dê importância à sociologia. Na mesma direção, Chervel (1990, p. 187) destaca que é por meio da relação estabelecida para tal, com nossos estudantes, que nos cabe refletir sobre os conteúdos ensinados e, logo, sobre o lugar e o papel da disciplina:

Fruto de um diálogo secular entre os mestres e os estudantes, elas constituem por assim dizer o código que duas gerações, lentamente, minuciosamente, elaboraram em conjunto para permitir a uma delas transmitir a outra uma cultura determinada (Chervel, 1990, p. 222).

\section{0 lugar da Sociologia}

O entendimento sobre o lugar ocupado pelo ensino de sociologia nos últimos anos exige reflexões que integrem diversos elementos: a história da disciplina e suas relações com a área de conhecimento e as políticas e reformas educacionais, além da vida cotidiana da escola, refletida pela cultura escolar. Nesse sentido, o pressuposto central da investigação é o de que, na metodologia sociológica, um dos elementos imprescindíveis para a compreensão dos fenômenos sociais é a relação causal que estes têm, ou seja, que nenhum aspecto da ação social do comportamento humano pode ser explicado por uma determinante, mas, sim, por uma correlação de fatores e de suas diversas possibilidades: "Deve ser uma das primeiras tarefas da investigação sociológica e histórica analisar todas as influências e relações causais que possam ser explicadas satisfatoriamente em termos de reação ao meio ambiente" (Weber, 2004, pp. 32-33).

Não é tarefa deste trabalho, mas há que ressaltar a importância de pensar no lugar da Sociologia como área do conhecimento, o que levaria a questionamentos sobre seu papel na produção do conhecimento em relação às outras áreas e, consequentemente, 
outras disciplinas. Tal aspecto, ou seja, a importância da Sociologia no campo da pesquisa, pode ter também influenciado nas entradas e saídas da sociologia nos currículos educacionais, bem como na classificação dentro do espaço escolar das disciplinas. A organização escolar, fruto da construção efetuada por meio do desenvolvimento da cultura escolar, econômica e social, está pautada para se pensar na formação dos estudantes em disciplinas, logo o campo da sociologia precisa discutir seus percalços.

A intermitência da presença da sociologia como disciplina obrigatória pode ter feito com que não tenha, até o momento, conseguido participar do cotidiano escolar de forma efetiva, nem ter sido absorvida pela cultura escolar, o que reflete na dificuldade em reorganizá-la e legitimá-la. Apesar dos parâmetros que regem a educação e dos profissionais da área destacarem a importância do ensino de sociologia a fim de contribuir para a criação de um ponto de vista crítico aos estudantes e causar-lhes um estranhamento a respeito do mundo, parece que a cultura criada na escola serve como uma forte barreira para a efetivação e o entendimento desta importância, pois a disciplina de sociologia encontra as disciplinas já classificadas e impede que os sujeitos que participam do cotidiano escolar tomem consciência de sua importância na formação educacional. A classificação em grau de importância das disciplinas escolares, estabelecida pelo tempo de oferta, pela incompreensão de suas finalidades e pela forma singular e desanimada como os professores da própria disciplina conduzem seus trabalhos, podem ser meios pelos quais os sujeitos desenvolvem seus significados a respeito das disciplinas, refletidos em seus hábitos e comportamentos. Apesar de parecer não entender o sentido de várias outras disciplinas escolares, os estudantes se comportam de maneiras distintas em relação a elas, conotando, a cada uma, certo grau de importância.

O papel do professor de cada disciplina é fundamental no processo de valorização e entendimento da importância da disciplina no conjunto, pois são eles os responsáveis por elaborar e 
desenvolvê-las, ajudando os estudantes a atribuírem sentido, importância e valor. Para atingir tal objetivo é que se faz importante a formação dos professores de sociologia nos cursos de licenciatura. Ter um professor identificado com a área e com os aspectos metodológicos da profissão é essencial, pois somente um professor/profissional identificado com a sociologia e bem formado pedagogicamente pode contribuir para que se crie uma cultura escolar que adote a sociologia como disciplina importante ou que legitime a importância da sociologia dentro das escolas. Nesse sentido, a reforma do ensino médio pode efetuar uma ruptura no que vinha sendo feito em termos de contratação de professores formados na área e da diminuição da presença da disciplina ou mesmo de sua exclusão, passando apenas a figurar entre conteúdos muitas das vezes sem o devido cuidado sociológico.

A crítica feita por Julia (2001), acerca dos estudos demasiados externalistas referentes à escola, faz sentido, pois uma vez analisado somente a obrigatoriedade da disciplina de sociologia e seus manuais e diretrizes de ensino, poderíamos conceber que o ensino de sociologia estava sendo aplicado nas escolas de tal modo como previsto na lei. Entretanto, bastou seguir os passos aconselhados por Julia (2001) e voltar o olhar às práticas do interior da escola, para notar que na realidade os fatos não seguem estritamente o que está previsto legalmente.

O fato da disciplina de sociologia voltar a figurar nos currículos da escola como disciplina obrigatória poderia garantir-lhe legitimidade, importância e prestígio, mas parece que há uma realidade bastante diferente. Parece ter sido constituída uma hierarquização das disciplinas que rege e é regida pelo comportamento a respeito dos saberes escolares que influencia os estudantes a elaborarem os significados a respeito das diferentes disciplinas escolares. A incorporação desses comportamentos, como destaca Julia (2010, p. 2), pode, também, ser realizada dentro da própria escola, através da cultura escolar. Os estudantes haviam aprendido hábitos e comportamentos diferentes em relação às disciplinas escolares. 
No que se refere aos conteúdos e à sua relação com o currículo, um dos professores observados chegou a mudar completamente seu plano de ensino de sociologia, levando em consideração o perfil dos estudantes da escola, a fim de que os conteúdos se tornassem mais atrativos e fossem apreendidos pelos estudantes. As políticas educacionais têm destacado a importância dos conteúdos se centrarem ou partirem da realidade do estudante para explicar conceitos e teorias. Mas o que esses estudantes sabem sobre sociologia? Teriam condições de definir conteúdos ou indicar caminhos? A realidade do estudante já é conhecida por ele, então tem-se que ensinar o novo, o conteúdo para que ele possa, com a ajuda do professor, problematizar e compreender com um olhar diferente as situações e a realidade na qual ele vive. É um perigo pensar que devemos sempre partir da vivencia do estudante, pois os currículos podem ficar pobres de conteúdo e o ensino enfraquecido e superficial. Segundo Young (2011, p. 612), as atuais políticas educacionais têm negligenciado questões fundamentais a respeito do conhecimento e dão muita ênfase nos aprendizes, gerando um esvaziamento de conteúdo, especialmente para os estudantes que já não têm sucesso na escola. Para Young (2011, p. 610), a questão do conhecimento deve ser central na formulação das políticas educacionais curriculares, em que a abordagem curricular deve ser baseada no conhecimento e na disciplina e não nos estudantes, como se tem feito atualmente.

Há um longo caminho a ser percorrido no que se refere à absorção da sociologia nos currículos e na cultura escolar, mesmo se houver outra vez a opção em introduzir apenas conteúdos e não como uma disciplina. Conforme destaca Chervel (1990, p. 218), há um trabalho de enfrentamento para fazer com que a sociologia modifique a cultura escolar que não a reconhece como importante:

Quando uma disciplina, que não era dispensada até então, se instala solidamente na instituição, quando ela produziu seus efeitos sobre uma geração inteira de estudantes, por vinte ou trinta anos ao menos, ela é forçosamente recolocada em questão por seu próprio sucesso. Sua existência 
continuada não é automática, como se poderia ser tentado crer. Pois ao término desse período probatório, ela se dirige a partir de então às crianças ou adolescentes cujos pais e o meio familiar receberam uma aculturação que fazia falta totalmente às famílias dos estudantes de trinta anos antes. Uma parte, ao menos da disciplina, está, entrementes, integrada às aprendizagens familiares e sociais. Os estudantes beneficiam-se então de uma "pré-aculturação", ou de uma "peri-aculturação", que enriquece um pouco mais a bagagem que levam consigo para a escola. 0 ensino é, pelo menos, facilitado; as etapas são transpostas com mais vivacidade; os bloqueios de antigamente desaparecem. $\mathrm{E}$ a disciplina deve mudar seus métodos. Por vezes, ela desaparece dos programas, e cede lugar a outras urgências, não tendo sido necessária senão uma rodada para modificar a cultura da sociedade global (Chervel, 1990, p. 218).

\section{Considerações finais}

Após mais de oito anos da volta da obrigatoriedade da disciplina de sociologia no ensino médio e em meio a modificações desta condição, ocasionados pela reforma do ensino médio, as dificuldades em colocá-la de fato em prática são grandes, pois os professores e estudantes não entendem o objetivo e o lugar da disciplina na cultura escolar.

De acordo com os PCNs para o ensino médio de 2006, a sociologia deveria cumprir importante papel na formação dos estudantes por trabalhar dois aspectos fundamentais para a formação do cidadão e da consciência crítica, que são a desnaturalização e o estranhamento. Porém, os relatos apresentados sobre a escola em questão indicam haver um distanciamento de tais ideais. Como não entendem o sentido, o motivo da disciplina de sociologia estar novamente presente dentro das grades curriculares das escolas brasileiras, ou por resistirem ao modelo escolar, não são tocados a compreender a importância desta disciplina para a formação dos jovens, por meio do estudo sistematizado da realidade social, com o conhecimento de conceitos que ajudem a organizar o pensamento e refletir sobre $o$ 
processo histórico-social de constituição dos grupos sociais. Talvez caiba ao professor de sociologia refletir sobre a questão, apesar de se afirmar não ser ele o único responsável pelas dificuldades enfrentadas, mas o mais capaz para modificá-la.

O papel desempenhado pela cultura escolar é fundamental para entender o processo pelo qual a disciplina de sociologia ainda não é dotada de sentido e de importância, uma vez que os sujeitos que participam do cotidiano escolar classificam as disciplinas escolares através dessa cultura produzida dentro da escola, apesar de afetada pelo contexto socioeconômico. Dentre os aspectos que contribuem para a classificação estão as práticas dos professores de sociologia, a incompreensão sobre o sentido da sociologia pelos estudantes, o distanciamento entre o propagado pelos documentos oficiais e as realidades escolares e o histórico de intermitência da disciplina de sociologia nos currículos. Uma disciplina que costumeiramente entra e sai dos currículos escolares pode ter sido definida pela cultura escolar como secundária, já que a qualquer momento pode ser retirada, não contendo a mesma importância dada às demais. Fato que pode ser agravado, mais uma vez, com a implantação da reforma do ensino médio.

Por meio de um olhar direcionado às práticas escolares, foi possível apreender diversos comportamentos que deixaram transparecer uma hierarquização das disciplinas escolares. A disciplina de sociologia é reservado um lugar secundário e inferior às demais disciplinas do currículo, fato percebido pelo comportamento dos estudantes e dos professores de outras disciplinas dentro da escola e dos significados atribuídos à ela, colocando-a em um lugar inferior na hierarquia dos saberes.

\section{Referências}

APPLE, Michael; BURAS, Kristen L. Introdução. In: Currículo, poder e lutas: com a palavra os subalternos. Porto Alegre: Artmed, p. 9-46, 2008. 
APPLE, Michael W. Reprodução, contestação e currículo. In: Educação e poder. Porto Alegre: Artes Médicas, p. 19-54, 1989.

APPLE, Michael. História do currículo e o controle social. In: Ideologia e currículo. São Paulo: Brasiliense, p. 95-123, 1982.

BAUMAN, Zygmund. Ensaios sobre o conceito de cultura. Rio de Janeiro: Zahar, 2012.

BRASIL. Senado Federal. Projeto de Lei de Conversão n.o 34/2016. Disponível em: http://www25.senado.leg.br/web/atividade/materias/-/materia/126992. Acessado em 17/02/2017, 2017.

Presidência da República. Lei no. 11.684 de 02 de junho de 2008. Estabelece as diretrizes e bases da educação nacional, para incluir a Filosofia e a Sociologia como disciplinas obrigatórias nos currículos do ensino médio. Disponível em: http://www.planalto.gov.br/ccivil_03/_Ato2007-2010/2008/ Lei/L11684.htm. Acessado em: 20 jan. 2013, 2008.

Ministério da Educação. Secretaria de Educação Básica. Orientações curriculares para o ensino médio. Brasília: Disponível em: http://portal. mec.gov.br/seb/arquivos/pdf/book volume 03 internet.pdf. Acessado em: 10 fev. 2013, 2006a.

. Ministério da Educação. Secretaria de Educação Básica. PCN + Ensino Médio: Ciências Humanas e suas Tecnologias. Brasília. Disponível em: http://portal.mec.gov.br/seb/arquivos/pdf/CienciasHumanas.pdf. Acesso em: 10 fev. 2013, 2006b.

. Ministério da Educação. Secretaria de Educação média e Tecnológica.

Parâmetros curriculares nacionais (ensino médio). Brasília. Disponível em: http://portal.mec.gov.br/seb/arquivos/pdf/blegais.pdf. Acessado em: 07 mar. 2013, 2000.

. Presidência da República. Lei no. 9.394 de 20 de dezembro de 1996. Lei de Diretrizes e Bases da Educação Nacional. Disponível em: http://portal. mec.gov.br/arquivos/pdf/ldb.pdf. Acessado em: 20 jan. 2013.

CHERVEL, André. História das disciplinas escolares: reflexões sobre um campo de pesquisa. Teoria e Educação, n. 2, p. 177-229, 1990.

JULIA, Dominique. A cultura escolar como objeto histórico. Revista Brasileira de História da Educação, n.1, p. 9-43, 2001.

KRAWCZK, Nora Rut. Políticas de regulação e mercantilização da educação: socialização para uma nova cidadania? Educação e Sociedade, n. 92, p. 799-819, 2005. LIEDKE FILHO, Enno D. A sociologia no Brasil: história, teorias e desafios. Sociologias, n. 14, p. 376-437, 2005. 
MORAES, Amaury César. Licenciatura em ciências sociais e ensino de sociologia: entre o balanço e o relato. Tempo social, n. 1, p. 5-20, 2003.

. Ensino de sociologia: periodização e campanha pela obrigatoriedade. Cadernos Cedes, n. 85, p. 359-382, 2011.

SANTOS, Mario Bispo dos. A sociologia no ensino médio: o que pensam os professores da rede pública do Distrito Federal. 2002. Dissertação (Mestrado em Sociologia) - Instituto de Ciências Sociais, Universidade de Brasília, Brasília.

SILVA, Ileizi et al. 0 ensino de ciências sociais: mapeamento do debate em periódicos das ciências sociais e da educação de 1940-2001. Anais do XII Congresso Nacional de Sociólogos. Curitiba, 1 a 4 de abril, 2002.

STEMPKOWSKI, Ivete F. A influência social na construção do conhecimento: a formação dos currículos de sociologia no Ensino Médio. 2010. Dissertação (Mestrado em Ciências Sociais), Faculdade de Filosofia e Ciências Humanas, Pontifícia Universidade Católica do Rio Grande do Sul, Porto Alegre.

TORRES, Rosa Maria. Melhorar a qualidade da educação básica? As estratégias do Banco Mundial. In: WARDE, Mirian J. (org.). 0 banco mundial a as políticas educacionais. São Paulo: Cortez, p. 125-194, 1996.

VIÑAO, Antonio. Culturas escolares y reformas (sobre la natureza histórica de los sistemas e institcuciones educativas). Teias, n. 2, p. 99-133, 2000.

YOUNG, Michael F.D. 0 futuro da educação em uma sociedade do conhecimento: o argumento radical em defesa de um currículo centrado em disciplinas. Revista Brasileira de Educação, n. 48, p. 609-623, 2011.

WARDE, Mirian J.; CARVALHO, Marta M. C. de. Política e cultura na produção da história da educação no Brasil. Contemporaneidade e Educação, São Paulo, n. 7, p. 9-33, 2000.

WEBER, Max. A “objetividade” do conhecimento das Ciências Sociais. In: COHN, Gabriel (org.). Max Weber: sociologia. São Paulo: Ática, p. 79-127, 2006.

. A ética protestante e o espírito do capitalismo. São Paulo: Martin Claret, 2004.

Recebido em 27/03/2017

Aprovado em 30/09/2017 